\title{
The Convention on Biological Diversity's 2010 target
}

\begin{abstract}
Andrew Balmford, Leon Bennun, Ben ten Brink, David Cooper, Isabelle M Côté, Peter Crane, Andrew Dobson,* Nigel Dudley, Ian Dutton, Rhys E Green, Richard D Gregory, J eremy Harrison, Elizabeth TKennedy, Claire Kremen, Nigel Leader-Williams, Thomas E Lovejoy, Georgina Mace, Robert May, Phillipe Mayaux, Paul Morling, J oanna Phillips, Kent Redford, Taylor H. Ricketts, J on Paul Rodríguez, M Sanjayan, Peter J Schei, Albert S van J aarsveld and Bruno A Walther
\end{abstract}

\begin{abstract}
Governments are often accused of responding only to short-term and parochial considerations. It is therefore remarkable that representatives of 190 countries recently committed themselves at the Convention on Biological Diversity to reducing biodiversity loss. This presents conservation biologists with perhaps their greatest challenge of the decade. The authors of this Policy Forum describe approaches to identifying more of the earth's biological diversity; understanding how biological, geophysical, and geochemical processes interact; and presenting scientific knowledge in time to contribute to and achieve the 2010 target.
\end{abstract}

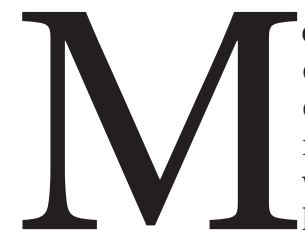

ost of the time, most of us behave as if our ongoing destruction of biological diversity and natural ecosystems has a net beneficial effect on our personal well- being. This is because it often haslocally, in the short term, and for people with the most power. However, when a longer-term view is taken, conserving biodiversity and the services it provides emerges as essential to human self-interest $[1,2]$. Representatives of 190 countries at the 2002 Johannesburg World Summit on Sustainable Development committed themselves to "...achieving by 2010 a significant reduction of the current rate of biodiversity loss at the global, regional, and national level..." [3]. By adopting the 2010 target, governments are explicitly recognizing the value of biodiversity, setting goals for its conservation, and holding themselves accountable $[4,5]$.

These undertakings present conservation scientists with a great challenge. The 2010 target can only catalyze effective conservation if systems are in place to tell governments, businesses, and individuals about the consequences of their actions. Yet we have so far identified only a fraction of the earth's biological diversity and have just a rudimentary understanding of how biological, geophysical, and geochemical processes interact to contribute to human wellbeing. How can we present our knowledge in ways that are useful to decision-makers and in time to contribute to achieving the 2010 target?

\section{The need for indicators}

Part of the answer lies in establishment of indicators of biodiversity and ecosystem functions and services that are rigorous, repeatable, widely accepted, and easily understood. Conservation scientists have a lot to learn in this regard from economists, who have long had a set of common and clear indicators for tracking and influencing market development. Recently, biologists adopted a similar approach by producing composite indicators from population time series data on widely studied groups such as birds and other vertebrates [3, 6-10]. One of these, the UKWild Bird Index, has already been adopted by the UK government as an indicator of quality of life and a measure of how well environmental policies are working [6, 11]; because of well-understood links with farming practices [12], this index could soon be extended to the European Union (EU) to inform the reshaping of its Common Agricultural Policy [6].

The first step toward developing global indicators has already been taken. In early 2004, parties to the Convention on Biological Diversity (CBD) established a framework for assessing progress on the 2010 target (United Nations Environment Programme (UNEP) [13]; see table). For these indicators to gain wider scientific respect and be used more broadly, they will require continuing independent scientific assessment and input. In July 2004, the Royal Society (UK) invited more than 60 scientists from governments, academia, and global and national conservation organizations (representing 15 countries) to a workshop designed to review the indicators and to explore how such input could be provided.

Workshop participants concluded that the 18 indicators already identified are likely to provide useful information but also will leave important gaps in our understanding of biodiversity loss. Additional indicators were proposed that could provide some of the missing information by 2010. A comprehensive set of indicators may need to be larger still (e.g., see 102 indicators for taking the pulse of US ecosystems [14]). However, workshop participants recognized that developing indicators would not be enough.

\section{Broadening the science}

Fundamentally, we need to develop models that describe how the human, biological, physical, and chemical components of the earth system interact. Sketching the scope of such models (see 'supporting online material') brings home the fact that while we have little detailed and quantitative information on many components of the system, we know even less about how the linkages between them work. Developing models would guide data collection, help quantify how ecosystems benefit humans, clarify mechanisms by which activities and policies affect biodiversity and the services it provides, and allow improved projections about what might happen in the future. Part of the work of the Millennium 
Ecosystem Assessment [15] is to build models of this kind, but this effort needs to be continued and extended.

Most of the indicators so far under discussion deal with biodiversity per se and principally involve biologists. Studies linking socio-economic factors and geophysical and geochemical processes with biodiversity are relatively undeveloped. Given the contributions that biodiversity conservation will make toward alleviating poverty $[16,17]$, it is crucial that indicators and models address all components.

Reducing the rate of loss of a plant or animal species is only a step in the right direction and may not prevent extinction. Likewise, preventing further decline and even allowing modest recovery, for example, of a depleted fish stock, might not be sufficient to allow sustainable exploitation [18]. Policymakers may need to consider more ambitious targets, such as halting loss and restoring ecosystems. This was already accepted by the EU Council at its meeting in Göteborg, Sweden, in 2001 and by the European Environment Ministers at Kiev, Ukraine, in 2003 [19].

There are also immediate needs for global extension of monitoring programs and developments in capacity building, design of data collection programs, quality control, and statistical analyses. Most indicators likely to be available in the near future will be based on existing databases and monitoring schemes. However, as the areas richest in biological diversity are often those most lacking resources, current databases and monitoring are usually not fully representative and do not cover a wide enough range of system components. Meta-analyses of other existing, if scattered, data offer considerable scope for plugging some gaps quickly [20]. Another possibility is the use of remote sensing to measure both currently and retrospectively the extent and condition of biomes. This approach is already well developed for measuring changes globally in forests [21].

\section{The challenge}

The 2010 target provides the scientific community the challenge to engage in exciting fundamental science and to participate in what is likely to be the most significant conservation agreement of the early 21 st century. Models, indicators, data, and monitoring techniques must be open to scrutiny.

CONVENTION ON BIOLOGICAL DIVERSITY'S FRAMEWORK FOR ASSESSMENT BY 2010

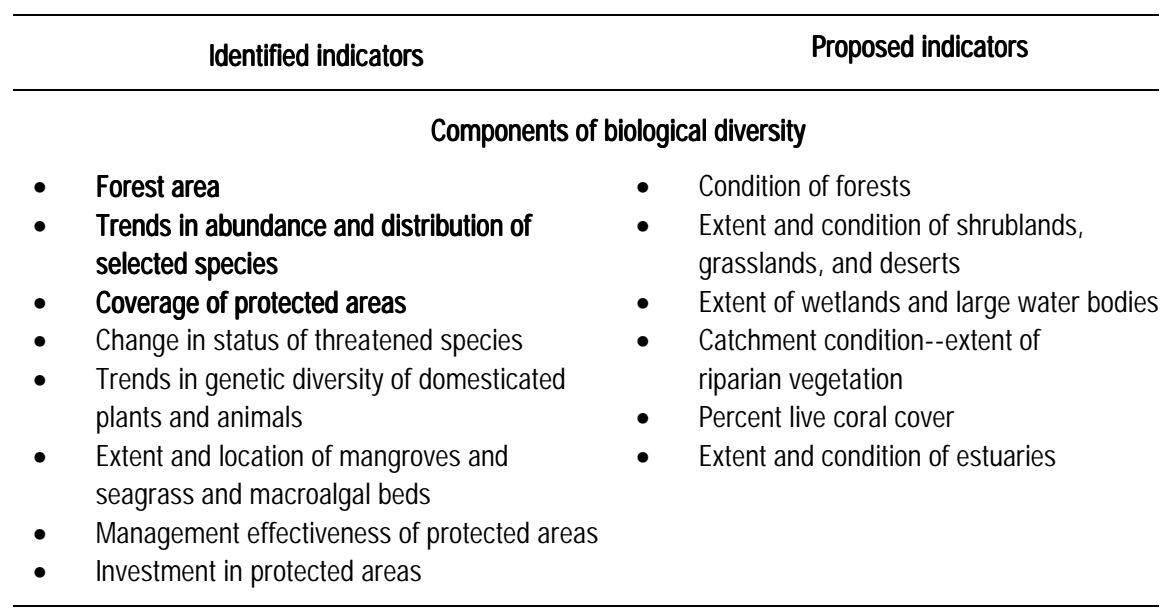

\section{Sustainable use}

- Area of forest, agriculture, and aquaculture under sustainable management

- Proportion of products derived from sustainable sources

\begin{tabular}{lll}
\hline & \multicolumn{2}{c}{ Threats to biodiversity } \\
- Nitrogen deposition & - Marine fishing effort \\
- Number and cost of alien invasions & - Road-free area \\
& - Epidemic outbreaks among wild species
\end{tabular}

Ecosystem integrity, goods, and services

- Marine trophic index

- Water quality in inland waters

- Freshwater trophic index

- Connectivity and fragmentation of ecosystems

- Incidence of human-induced ecosystem failure

- Health and well-being of people in biodiversity-dependent communities

- Biodiversity use in food and medicine

- $\quad$ Fish harvest per unit effort

- Timber and fuelwood harvest per unit effort

\section{- Status and trends of linguistic diversity and numbers of speakers of indigenous languages}

\section{Resource transfers}

\section{- Official development assistance in support of CBD}

The CBD framew ork for assessing progress. The 18 indicators already identified for immediate testing (bold) and future development (not bold) are shown plus indicators suggested by the Royal Society workshop and potentially available by 2010 . Workshop recommendations can be viewed at www.twentyten.net.

Interdisciplinary collaboration will be essential to strengthen the scientific rigor of the indicators, to enhance their relevance to policy, and to raise public awareness of their usefulness. Scientists must act in four key ways: (i) work with the CBD Secretariat and its partners to develop, review, and use the indicators already identified by the CBD Conference of Parties [22]; (ii) develop research and monitoring programs; (iii) share information and experience regarding development and implementation of monitoring programs, data management, and sharing; and (iv) promote increased 
availability of funds for long-term research and monitoring programs.

Economic indicators like gross domestic product (GDP) and financial indicators like the Dow Jones have set the precedent. The global imperative to protect biodiversity and ecosystem services must become as politically significant as economic growth, and the reasons for reducing the rate of loss of biological diversity need to be as widely understood and valued by the public and by governments. Well-conceived, robust, and understandable indicators can help achieve this objective. Yet time is fast running out: We are already approaching the half-way mark of this extraordinary chance for global conservation.

Reprinted with permission from Science, Vol 307, Issue 5707, page 212-213, issue of 14 J anuary 2005 [DOI: 10.1126/science.1106281]. Copyright (c) 2005 by The American Association for the Advancement of Science. All rights reserved.

Author affiliation in order listed: Cambridge University and University of Cape Town; BirdLife International; Netherlands Environmental Assessment Agency (RIVM); Convention on Biological Diversity (CBD) Secretariat; University of East Anglia; Royal Botanic Gardens, Kew; Princeton University; Equilibrium; The Nature Conservancy; Royal Society for the Protection of Birds and Cambridge University; Royal Society for the Protection of Birds; United Nations Environment Programme (UNEP) World Conservation Monitoring Centre; Conservation International; Princeton University; University of Kent; Heinz Center for Science, Economics and the Environment; Zoological Society of London; Oxford University; European Commission (EC) Joint Research Center; Royal Society for the Protection of Birds (twice); Wildlife Conservation Society; World Wildlife Fund, USA; Instituto Venezolano de Investigaciones Científicas; Diversitas and Fridtjof Nansen Institute; The Nature Conservancy; Stellenbosch University; Cambridge University. The views expressed in this article are the authors' and do not necessarily reflect the views of the organizations to which they are affiliated.

Author for correspondence: Andrew Dobson; E-mail: dobber@princeton.edu.

With an especial arrangement with The American Association for the Advancement of Science, online full text of this article has been made available to $\mathrm{HJ} \mathrm{S}$ free of cost. Visit our website for the link. The offer expires at the end of August 2006.

\section{References and Notes}

1 GC Daily (ed). 1997. Nature's Services. Washington, DC: Island Press
2 A Balmford, A Bruner, P Cooper, R Costanza, S Farber, R E. Green, M Jenkins, P Jefferiss, V Jessamy, J Madden, K Munro, N Myers, S Naeem, J Paavola, M Rayment, S Rosendo, J Roughgarden, K Trumper, and RK Turner. 2002. Economic reasons for conserving wild nature. Science 297: 950-953

3 UNEP. 2004. Decisions adopted by the conference of the parties to the convention on biological diversity at its sixth meeting. Report on the Sixth Meeting of the Conference of the Parties to the Convention on Biological Diversity (UNEP/CBD/COP/6/20/Part 2) Strategic Plan Decision VI/26" (CBD, 2002), The Hague, 2002 April 7-19. Available: www.biodiv.org/doc/meetings/cop/cop06/official/cop-06-20-part2-en.pdf

4 European Council. 2001. Presidency conclusions. Göteburg Council; 2001 June 15 and 16 (SN/200/1/01 REV1, EC, Brussels, 2001). p 8

5 Decision No. 1600/2002/EC of the European Parliament and of the Council of 22 July 2002 laying down the Sixth Community Environment Action Programme, Article 6.

6 RD Gregory et al., Philos. Trans. R. Soc. London Ser. B, in press

$7 \quad$ J Loh et al., Philos. Trans. R. Soc. London Ser. B, in press

8 D Pauly et al., Philos. Trans. R. Soc. London Ser. B, in press

9 SHM. Butchart et al., Nature, in press

10 BJE ten Brink. 2000. Biodiversity indicators for the Organization for Economic Cooperation and Development environmental outlook and strategy: A feasibility study. Bilthoven, Netherlands: National Institute for Public Health and the Environment (RIVM) report 402001014

11 DEFRA. 2002. Achieving a better quality of life: Review of progress towards sustainable development. London: Department for Environment, Food, and Rural Affairs

12 PF Donald, RE Green and ML Heath. 2001. Agricultural intensification and the collapse of Europe's farmland bird populations. Proceedings of Royal Society of London Series B 268: 25-29

13 UNEP. 2004. Decisions adopted by the Conference of the Parties to the Convention on Biological Diversity at its seventh meeting (UNEP/CBD/COP/7/21/Part 2), Decision VII/30 (CBD 2004). Available: www.biodiv.org/decisions/

14 Heinz Center. 2002. The State of the nation's ecosystems: Measuring the lands, waters, and living resources of the united states. Cambridge: Cambridge University Press

15 Millenium Ecosystem Assessment. 2003. Ecosystems and human well-being: A framework for assessment. Washington, DC: Island Press. $245 \mathrm{p}$

16 WM Adams, R Aveling, D Brockington, B Dickson, J Elliott, J Hutton, D Roe, B Vira and WWolmer. 2004. Biodiversity conservation and the eradication of poverty. Science 306: 1146-1149

17 K Homewood. 2004. Policy, environment and development in African rangelands. Environmental Science and Policy 7: 125

18 JA Hutchings, JK Baum, Philos. Trans. R. Soc. London Ser. B, in press

19 UNEP. 2003. Proposed biodiversity indicators relevant to the 2010 target (UNEP/CBD/SBSTTA/9/INF/26, Montreal, 2003)

20 IM Côté et al., Philos. Trans. R. Soc. London Ser. B, in press

21 P Mayaux et al., Philos. Trans. R. Soc. London Ser. B, in press

22 www.biodiv.org/2010-target

Supporting online material

www.sciencemag.org/cgi/content/full/307/5707/212/DC1 